\title{
Reflections on Creating a Multi-Site, Mixed Methods, and Interpretive Assessment Project
}

\author{
Darren llett and Natasha Floersch \\ University of Northern Colorado, USA
}

Emily Dommermuth, Juliann Couture, and Lindsay Roberts
University of Colorado Boulder, USA

Kristine Nowak, Jimena Sagàs, and Renae Watson

Colorado State University, USA

\section{Introduction}

In this paper, we reflect on the experiences of our research team in conducting a multi-site, mixed methods, and interpretive project concerning first-generation students and academic libraries. After a description of the context of the study and of our research methods, we examine both the strengths of the project and the challenges we encountered, with the aim of providing recommendations for library researchers who may be interested in pursuing a similar project.

\section{Context}

A team of library professionals from three public universities in Colorado collaborated on a mixed-method research project to explore the experiences of first-generation college students across Colorado universities. We sought to understand students' campus experiences, especially in using academic libraries. An understanding of the mindsets and skills first-generation students bring with them to college, as well as the challenges they face on campus and when using the libraries, could help to provide insights to improve library spaces, services, and collaborations with campus programs that serve first-generation students.

The research team included library professionals from the University of Colorado Boulder (CU Boulder), Colorado State University (CSU), and the University of Northern Colorado (UNC). All three are public, doctoral-granting institutions with largely residential student populations, but there are some notable differences among the universities.

CU Boulder has an approximate student population of 33,200. Of those students, $59 \%$ are in-state Colorado students and $13.8 \%$ are first-generation students. CU Boulder's University Libraries has five libraries. It is a comprehensive graduate research university and is known as the flagship university in the state of Colorado. CSU is located in Fort Collins, Colorado. Its student population is 31,600 students, of whom $70 \%$ are in-state students and $18.5 \%$ are first-generation students. CSU has a main library and one branch library. It was founded as a land-grant school and retains outreach to communities across Colorado in its mission. UNC is located in Greeley, Colorado. The student population is approximately 12,000 students, of whom $83 \%$ are instate students and $41 \%$ self-identify as first-generation students. UNC has two libraries. It was founded as a normal school and continues to be known for excellence in the field of education.

Our three campuses have much in common, particularly that they are public, doctoral granting, primarily residential universities. However, our histories, missions, and student bodies differ substantially. We recognize that not all types of higher education institutions are represented in this research project, but we hope that the range of student experience is broad enough to prove relevant for library professionals at a variety of institutions. 


\section{Methods}

The project grew out of conversations among the team members through professional networking channels. We discovered a shared interest in better serving first-generation students in our libraries. While some team members already worked closely with campus units that serve first-generation students, others were interested in expanding their work with this substantial campus population. Just over a year ago, we began meeting roughly once a month, usually online but occasionally in person, alternating among our three campuses. Early on, we agreed on the main outline of the project, namely that it would be a multi-site, mixed methods, interpretive/constructivist study. We chose to collect data at multiple sites instead of a single site to increase the number of potential participants as well as to "show the particular and unique as well as what is common to all" sites. ${ }^{1}$ In addition, a mixed methods design promised "a more complete understanding of a problem" through the use of both quantitative and qualitative data that complemented each other. ${ }^{2}$ The choice to use an interpretive/constructivist framework stemmed from our shared philosophy that "there are multiple realities, or interpretations, of a single event," and that meaning is created through social interactions. ${ }^{3}$ Further, this framework allowed us to focus on students' understandings of their experiences rather than evaluating them with a set of preconceived criteria.

After the initial planning stage, the research team developed a survey that contained both closed- and openended questions. The survey gathered demographic data, such as gender, race, and academic major. A set of Likert-scale questions addressed students' feelings regarding the importance of a range of library services and their comfort using those services as well as the frequency with which they actually used them. Further, the survey included open-ended questions regarding positive and negative experiences using the academic library. We distributed the survey to as many self-identified first-generation students at each of the three sites as possible, which varied substantially due to institutional contexts, structures, and policies. Respondents indicated at the end of the survey whether they would be interested in participating in individual, in-depth follow-up interviews.

We then conducted an initial analysis of the survey results and identified findings to be explored further in subsequent interviews. For example, there was a discrepancy between how important respondents felt library services were and how often they reported using them. As a team, we developed a research guide with five common interview questions. Yet we also developed individual questions tailored to the context of each institution. For instance, two of the institutions were particularly interested in information literacy instruction and therefore included questions about that topic in their interview guide. Interviews were audio recorded and subsequently transcribed. Next, we coded the transcriptions at each site to determine important themes in the interviews. Team members from another of the three institutions conducted a second round of thematic coding to increase intercoder agreement, that is, the extent to which we agreed in coding decisions. ${ }^{4}$

Team members divided analysis and writing tasks according to experience, interests, and availability. We came together regularly to confer, workshop data analysis techniques and tools, offer assistance and support, solve problems, select possible conferences and journals where we could submit our work, and coordinate writing and presentation of findings. We have presented initial findings at the Colorado Association of Libraries Conference and the First-Generation Southwest Symposium. For this current research experience paper, we gathered reflections on the research process from team members. Beyond this paper, we are writing an article that focuses on the qualitative findings and are planning a second, mixed methods article that draws from both the quantitative and qualitative data sets.

\section{Strengths \\ Research Team}

Several features of the research team and how we interacted contributed to our success in carrying out the project. Our varied backgrounds, research training, and experiences of working with first-generation students made for a culture of challenging discussions and mutual support. Team members shared knowledge and expertise from prior research projects, offering mutual advice and assistance, such as timesaving tips for more efficient interview transcription. During an in-person meeting, we practiced thematic 
coding using hard copies of transcripts and markers at first and then using Dedoose, the online tool we would later use to conduct coding. These workshop activities allowed us to interact in a different way, faceto-face and using hands-on tools. They drew on some team members' research expertise and appealed to varying work and learning styles. We also found that taking time to visit the three universities in person, gain a sense of the campuses and libraries, and get to know each other over a shared meal helped build trust, generate deeper conversation, and inform our collaboration.

Indeed, communication was a key factor at all stages of the research process, from research design to reporting findings. Regular meetings, virtually and occasionally in person, were integral in negotiating expectations, sharing responsibilities, and meeting goals. We often divided the project into subtasks, such as developing the survey instrument and writing the literature review. Small groups with representatives from each institution worked on those tasks. Having a knowledgeable and experienced team leader to guide the project, divide tasks, check in with teams, offer encouragement, and help us meet deadlines was a crucial element. Another factor that helped our research team collaborate successfully was striking a balance between defined roles and deadlines on the one hand and flexibility and understanding for team members' institutional and individual challenges and limitations on the other. Finally, our teamwork benefited greatly from an atmosphere of respect, trust, and humor. The diversity of the group was complemented by our shared goals and fundamental research perspective: to learn more about first-generation students' experiences using an asset-based approach in order to improve library services and eliminate barriers to library use.

\section{Research Design}

Another source of strength in this project was the research design. Beyond the advantage of an increase in potential research participants, the multi-site design of the project involved multiple researchers from three campuses. This plurality of voices made for a rich discussion of research design, drawing on our range of knowledge and skills. Some team members had more experience with quantitative research methods, for instance, and others with qualitative research. Another benefit of the multi-site design was the discovery of differences among our institutions. This research project provided an opportunity to examine our local practices in a new light and to consider changes that would have otherwise not occurred to us, such as coordinating disparate services to first-generation students on our campuses in order to avoid silos and to prevent duplication of effort. In addition, the fact that our findings reflected institutional differences may render them more relevant for library researchers working in a variety of contexts than if we had collected data at a single site.

A second prominent feature of the research design was the use of mixed methods. Multiple sources, collection methods, and types of data complemented and supplemented each other. For example, from the survey responses we learned that some students did not feel welcome in the academic library. Such preliminary findings later informed the development of our interview guide and the topics we explored indepth with interview participants. Qualitative data provided rich detail of personal experiences and viewpoints that illuminated quantitative findings from the survey. We discovered in the interviews, for instance, that students choose study spaces for a variety of reasons, from noise levels to feeling a stronger sense of belonging in other campus spaces, such as cultural centers or first-generation support program offices. Using a mixed methods design afforded us glimpses of issues from several perspectives. Taken together, the quantitative and qualitative portions of the project provided a fuller sense of first-generation students' attitudes toward and experiences of using academic libraries than if we had used a single method.

The third significant feature of our research design was the use of a constructivist or interpretive framework. This choice had several consequences for our project. We felt that the project should take into account the richness and nuance of students' experiences and viewpoints. Incorporating students' own voices was therefore of the utmost importance. This is especially true given the historical tendency in library and information science to frame first-generation students using a deficit model, an approach that includes frequent references to lower retention and graduation rates and other ways in which first-generation students purportedly differ from their continuing-generation counterparts. ${ }^{5}$ Using a constructivist or 
interpretive framework enabled us to highlight students' own understandings of their experiences, focus on their strengths, and discover the barriers that our institutions had created.

Thus, several features of our project contributed to its success. The characteristics and practices of the research team, such as the breadth of experience and knowledge in the team and positive communication habits, were crucial factors. Research design decisions, including our choice of data types and theoretical framework, were also fundamental to the effectiveness of the project.

\section{Challenges}

Despite a number of strengths, conducting the study provided a number of challenges as well. The challenges included working across three campus and library structures, securing funding for all stages of the research, and developing a foundation and shared understanding for the project.

\section{Campus and Library Structures}

Working across three campuses led to a number of challenges. There were differences in semester start and end dates, which affected when team members had time to devote to the study. This also influenced the timeline for completing interviews, as the approaching end of the semester created a need to quickly interview students before students left campus for the summer. We did not have sufficient time to communicate about how the interviews were going or to make adjustments to the interview guide as the interviews progressed, steps that could have increased the quality and consistency of the interview data across sites. In addition, scheduling regular virtual meetings and in-person meetings on each of the campuses was challenging due to varying semester dates.

In addition to differing academic calendars, our campuses had divergent structures for first-generation student support services. Some universities had a central office to serve first-generation college students and allowed the survey to be sent to all first-generation college students on that campus. This impacted our ability to communicate with potential survey respondents and resulted in varying response rates across sites. One university had separate first-generation student support services in each department, some of which agreed to distribute the survey and some of which did not, leading to greater survey response from students in particular majors and lack of responses from students in other majors.

The libraries on the three campuses had different priorities and strengths for their spaces and services, and members of the research team therefore had varying preferences for survey and interview questions. For example, some campuses had robust instruction programs and wanted to ask more specific questions about first-generation student experiences with library instruction. This led to challenges in balancing the individual campus preferences with the overall project goals. The solution was the development of common interview questions, so that comparisons and common themes could be drawn from all three campuses, as well as institution-specific questions so that each campus could collect data on their particular spaces and services.

\section{Funding}

Each campus had different levels of funding support for this research project, and we did not thoroughly consider all the possible costs when the project started. An initial funding need was to provide gift card incentives to encourage survey response and interview attendance; some campuses had more gift cards to offer students than others. The variation in funding led to discrepancies in the number of participants across sites. In addition, we did not anticipate the time commitment involved in transcription, and thus did not seek funding for professional transcription services.

Also linked to funding were varying research requirements and support. The three universities and the various types of positions in each library had disparate research and tenure expectations. This especially impacted the reporting stage of the research project, as we discovered that our respective institutions evaluated and valued conference presentations and publications differently. Further, team members had 
different levels of funding support to attend and present at conferences. These differences impacted the roles and levels of involvement of individual team members in presenting our findings.

\section{Foundation and Shared Understanding}

Larger-scale challenges that affected our research project through most of the stages included creating and adhering to a timeline; establishing shared understanding and priorities; managing a variety of working and communication styles; and learning to leverage our differences into strengths. These were all challenges that, upon later reflection, we could have focused on more at the beginning of the study. At times, it felt as if we were jumping ahead without sufficient planning due to our enthusiasm in learning about first-generation students in order to serve them better. For instance, we applied to our first conferences somewhat early. Though the impending deadline of a conference presentation is an excellent motivator, greater initial planning and development of common ground could have created more focused direction and greater efficiency.

By sharing some of the challenges we faced, from working across varied campus and library structures to securing funding and developing a foundation and shared understanding early in the project, we are able to share recommendations that may help other library researchers interested in undertaking a similar project.

\section{Recommendations}

We learned a number of lessons and have recommendations for conducting multi-site, mixed methods projects, including developing a strong shared understanding early in the project, taking time to thoughtfully collect data, carefully selecting the research tools and applications, and emphasizing flexibility and commitment to the research team and each other's strengths in addition to the products of the research. These recommendations draw from both the strengths and challenges of our project.

Starting with a strong foundation is key, particularly with a large-scale project. We recommend choosing collaborators deliberately. Shared research goals, compatible work styles, and experience with a variety of research methods and tools are beneficial. Further, the selection of research sites should align with the aims of the project. For example, including three public, doctoral-granting, residential universities provided a large pool of first-generation student research participants. However, including other types of higher education institutions, such as community colleges, private institutions, or commuter campuses, could have highlighted diverse student experiences that were not captured by this study. Other tasks we recommend spending substantial time on from the outset are: developing the theoretical foundation, mapping out the various steps of the project in detail, creating subteams to work on the various steps or aspects of the project, and clearly defining the roles for those subgroups. These steps can help ensure that all team members have a deep and shared understanding of the project and the practical requirements to carry it out. Finally, we recommend securing funding for each step of the project at the beginning to ensure that each campus can participate equally and fully in recruitment, data collection, transcription, data analysis, and reporting of findings.

We suggest allowing plenty of time to conduct interviews to enable team members to practice interviewing, conduct pilot interviews, reflect on initial interviews, discuss with team members, and make adjustments to the interview guide. ${ }^{6}$ These steps can improve the quality and consistency of data collection. We would also suggest including open-ended questions only when qualitative data are truly desired. For instance, our openended questions about commute time and academic major unnecessarily complicated data analysis. Closed question types would have provided sufficient information and streamlined analysis. In addition, though performing our own transcription increased our familiarity with the interview data, we recommend seeking funding for a professional transcription service to save time and ensure standardized transcripts.

Researchers can listen to the audio to review transcripts and gain familiarity with the data without spending a large amount of time and effort in transcription.

The online applications a team uses are another integral factor. We found web conferencing tools such as Zoom and productivity applications such as Google Drive essential to completing all stages of the project. In 
developing the survey, Qualtrics allowed for the creation of a unified instrument but also enabled us to brand and tailor it for each institution. We found that an automated transcription application such as Dragon yielded mixed results. Some research team members found that it saved them time in transcription. However, the quality of the transcriptions varied substantially due to such factors as the quality of the recordings, proximity of audio recorders to participants, and potential bias in the transcription application toward particular dialects or accents. The cloud-based coding application Dedoose enabled the team to develop, monitor, and discuss an emerging set of shared thematic codes across sites, though it did require training-and thus valuable time-for most team members to learn. The cloud-based citation management application Zotero allowed team members to gather sources, minimize duplication, and add comments to sources to aid in writing later. All of the applications offer no- or low-cost options. When there is a charge, we recommend exploring the possibility of sharing accounts, thereby minimizing cost.

No matter the level of careful planning and coordination, there is no way to foresee or prevent all challenges that may arise. We encourage flexibility and understanding for the hiccups that may occur at the individual and institutional levels. All of us are, after all, practicing library professionals who juggle multiple responsibilities and projects. Understanding, mutual support, and commitment to the research team (and not just the products of the research) are therefore vital parts of a successful collaboration.

\section{Conclusion}

From inception to dissemination of findings, our project was characterized by plurality. This was the case in terms of research sites, team members, research methods, and data sources. Such an approach offered a richness of perspectives and data, thereby resulting in a more comprehensive understanding of firstgeneration students' experiences with academic libraries. Nevertheless, that abundance brought with it a set of challenges in managing the team and the data. For library researchers considering a similar undertaking, we suggest a balance between planning and flexibility to manage the complexity of a multi-site, mixed methods, interpretive research project.

-Copyright 2019 Darren Ilett, Emily Dommermuth, Juliann Couture, Natasha Floersch, Kristine Nowak, Lindsay Roberts, Jimena Sagàs, and Renae Watson 
Notes

1. Bishop, "Multi-Site Case Study," 587.

2. Creswell and Plano Clark, Designing and Conducting, 65.

3. Merriam and Tisdell, Qualitative Research, 9.

4. Saldaña, The Coding Manual, 37.

5. For an example of the focus on first-generation students' differences from traditional students, see Tyckoson, "Library Service for the First-Generation College Student," 91-99.

6. Creswell and Poth, Qualitative Inquiry, 165.

\section{Bibliography}

Bishop, Pam. "Multi-Site Case Study." In Encyclopedia of Case Study Research. Edited by Albert J. Mills, Gabrielle Durepos, and Elden Wiebe, 587-590. Vol. 2. Thousand Oaks, CA: Sage Reference, 2010.

Creswell, John W. and Cheryl N. Ploth. Qualitative Inquiry and Research Design: Choosing among Five Approaches. 4th ed. Los Angeles: Sage, 2018.

Creswell, John W. and Vicki L. Plano Clark. Designing and Conducting Mixed Methods Research. 3rd ed. Thousand Oaks, CA: Sage, 2017.

Merriam, Sharan B. and Elizabeth J. Tisdell. Qualitative Research: A Guide to Design and Implementation. 4th ed. San Francisco: Jossey-Bass, 2016.

Saldaña, Johnny. The Coding Manual for Qualitative Researchers. 3rd ed. Los Angeles: Sage, 2016.

Tyckoson, David A. "Library Service for the First-Generation College Student.” In Teaching the New Library to Today's Users: Reaching International, Minority, Senior Citizens, Gay/Lesbian, First Generation, AtRisk, Graduate and Returning Students, and Distance Learners. Edited by Trudi E. Jacobson and Helene C. Williams, 89-105. New York: Neal-Schuman, 2000. 